\title{
Androgen receptor phosphorylation: biological context and functional consequences
}

\author{
Yulia Koryakina', Huy Q Ta ${ }^{1}$ and Daniel Gioeli ${ }^{1,2}$ \\ ${ }^{1}$ Department of Microbiology, Immunology, and Cancer Biology, and ${ }^{2}$ UVA Cancer Center, University of Virginia, \\ PO Box 800734, Charlottesville, Virginia 22908, USA
}

Correspondence should be addressed to $D$ Gioeli

Email

DGG3F@VIRGINIA.EDU

\begin{abstract}
The androgen receptor (AR) is a ligand-regulated transcription factor that belongs to the family of nuclear receptors. In addition to regulation by steroid, the AR is also regulated by post-translational modifications generated by signal transduction pathways. Thus, the AR functions not only as a transcription factor but also as a node that integrates multiple extracellular signals. The AR plays an important role in many diseases, including complete androgen insensitivity syndrome, spinal bulbar muscular atrophy, prostate and breast cancer, etc. In the case of prostate cancer, dependence on AR signaling has been exploited for therapeutic intervention for decades. However, the effectiveness of these therapies is limited in advanced disease due to restoration of AR signaling. Greater understanding of the molecular mechanisms involved in AR action will enable the development of improved therapeutics to treat the wide range of AR-dependent diseases. The AR is subject to regulation by a number of kinases through post-translational modifications on serine, threonine, and tyrosine residues. In this paper, we review the AR phosphorylation sites, the kinases responsible for these phosphorylations, as well as the biological context and the functional consequences of these phosphorylations. Finally, what is known about the state of AR phosphorylation in clinical samples is discussed.
\end{abstract}

\section{Key Words}

- androgen receptor

- cell signaling

- gene transcription

- growth factor

- prostate

\section{Introduction}

The androgen receptor (AR) consists of an N-terminal transcriptional regulatory domain (activation function 1 (AF1)) that can function in the absence of ligand, a DNAbinding domain (DBD), a hinge region, and a C-terminal ligand-binding domain (LBD) that also is associated with a second transcriptional regulatory function (AF2). The $\mathrm{N}$ - and C-terminal domains are involved in homotypic dimerization and bind to other transcriptional regulatory proteins. When not bound to ligand, the AR is sequestered with chaperones and is not concentrated in the nucleus. Following ligand binding, a nuclear import signal is exposed and the receptor becomes concentrated in the nucleus where it binds DNA; homodimerizes in a reaction that involves interactions between the $\mathrm{N}$ - and C-termini; and interacts with a constellation of transcriptional co-regulators, transcription factors, and components of the basal transcription machinery (Langley et al. 1995, Bubulya et al. 1996, 2000, 2001, Doesburg et al. 1997, Aarnisalo et al. 1998, Fronsdal et al. 1998, Tillman et al. 1998, Wise et al. 1998, Nessler-Menardi et al. 2000, Reutens et al. 2001, Wang et al. 2001, Gelmann 2002, Heinlein \& Chang 2002, Kotaja et al. 2002a,b, McKenna \& O’Malley

Published by Bioscientifica Ltd

This paper is one of 12 papers that form part of a thematic review section on

Androgens and the AR in Breastand Brostate Cancer. The Guest.Editors for this section : $43: 19 \mathrm{AM}$

$\begin{array}{ll}\text { were Wayne Tilley and Frank Claessens. via free access } & \end{array}$ 
2002a,b, Comuzzi et al. 2003). AR phosphorylation is commonly believed to alter AR activity by modifying the protein interactions described above.

The AR is phosphorylated on serine, threonine, and tyrosine residues and there are phosphorylations in each of the major protein domains (Fig. 1). The N-terminal domain, which encompasses the AF1 region, contains the majority of phospho-sites: S16, S81, S94, S213, Y223, S256, Y267, T282, S293, S308, Y363, S424, S515, and Y534. In the DBD, S578 is phosphorylated, in the hinge region S650 is phosphorylated, and in the LBD, which contains the AF2 domain, S791 and T850 are phosphorylated. Furthermore, under select conditions the AR is also phosphorylated on S405 and Y551/552. Below, we describe what is generally known about the AR phosphorylation sites where the proximal kinase(s) have been identified and some insights into the function of the phosphorylation

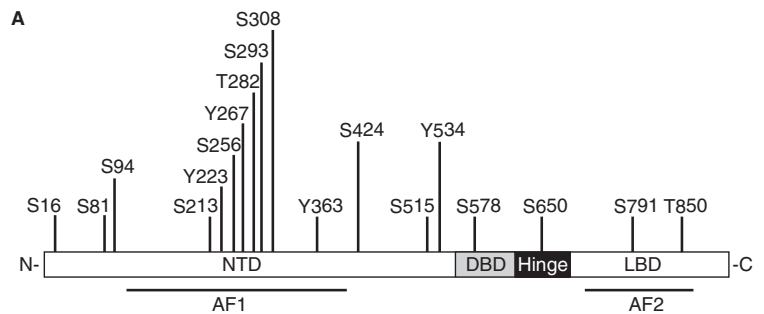

B

\begin{tabular}{|c|c|c|c|c|c|}
\hline Phospho-site & \multicolumn{4}{|c|}{ Function } & Kinases \\
\hline S81 & $\checkmark$ & $\checkmark$ & $\checkmark$ & $\checkmark$ & CDK1, CDK5, CDK9 \\
\hline S213 & $\checkmark$ & $v$ & $\checkmark$ & $v$ & Akt, PIM1 (L, S) \\
\hline Y223 & $\checkmark$ & & & & Fer \\
\hline Y267 & $\checkmark$ & & & $\checkmark$ & Ack \\
\hline T282 & $\checkmark$ & & & $\checkmark$ & Aurora-A \\
\hline S293 & $\checkmark$ & & & $\checkmark$ & Aurora-A \\
\hline S308 & $\checkmark$ & & & $\checkmark$ & $\mathrm{CDK} 11^{\mathrm{p} 58}$ \\
\hline Y363 & $\checkmark$ & & & & Ack \\
\hline S515 & $\checkmark$ & $\checkmark$ & & & CDK7, MAPK \\
\hline Y534 & $\checkmark$ & $\checkmark$ & & $\checkmark$ & Src, Etk \\
\hline S578 & $\checkmark$ & & & & PKC, PAK6 \\
\hline S650 & $\checkmark$ & & 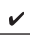 & & JNK, p38 \\
\hline T850 & $\checkmark$ & & & $\checkmark$ & PIM1L \\
\hline
\end{tabular}

\section{Figure 1}

(A) Schematic of the AR phosphorylation sites with the major functional domains is shown. NTD, N-terminal domain; DBD, DNA-binding domain; $L B D$, ligand-binding domain; AF1, activation function 1; AF2, activation function 2. (B) Overview of the AR phosphorylations, their corresponding kinases, and functional effects. Only those phosphorylation sites with an identified function are listed. Specific details are in the text. The amino acid numbering used in this review is based on NCB accession no. AAA51729 (Lubahn et al. 1988). site have been made. Not discussed in any detail are the following AR phosphorylation sites: S16, S94, S256, and S424; the kinases that phosphorylate these sites are currently unknown as is the function of these sites.

\section{S81 phosphorylation}

\section{Cyclin-dependent kinases phosphorylate S81}

The highest stoichiometric phosphorylation on the AR in response to hormone is $\mathbf{8 8 1}$, with phosphorylation on this AF1 region serine increases significantly over $8 \mathrm{~h}$ in androgen-treated prostate cancer cells (Gioeli et al. 2002). Multiple kinases, all from the cyclin-dependent kinase (CDK) family, have been reported to phosphorylate the AR on S81 (Chen et al. 2006, 2012, Gordon et al. 2010, Hsu et al. 2011, Gioeli \& Paschal 2012). CDKs are of significant interest as regulators of cancer cell proliferation and genomic integrity, leading to studies examining the viability of this family of proteins as therapeutic targets (Malumbres \& Barbacid 2009). Studies suggest that CDK1, CDK5, and CDK9 can phosphorylate the AR on S81 (Chen et al. 2006, Gordon et al. 2010, Hsu et al. 2011). Overexpression of CDK1 and AR in 293T cells increased both AR S81 phosphorylation and total AR protein levels, whereas treating both LNCaP cells and AR-transfected HeLa cells with the pan-CDK inhibitor, roscovitine, decreased S81 phosphorylation and total AR protein levels. Two other CDK inhibitors, with overlapping selectivity with roscovitine, also inhibited S81 phosphorylation and total AR levels, further suggesting that CDK1 activity regulates AR S81 phosphorylation in cells (Chen et al. 2006). S81 phosphorylation is higher in nocodazole-arrested cells, suggesting an increase in S81 phosphorylation in G2-M when CDK1 is active (Chen et al. 2012). The proteasome inhibitor, MG132, could reverse the decrease in AR protein resulting from CDK1 inhibition, although the S81A mutant was stabilized by overexpression of activated CDK1 similar to WT receptor, suggesting that this phospho-site is not necessary for the CDK1-mediated stabilization of the AR. CDK9 is also an AR S81 kinase (Gordon et al. 2010). CDK9 activity does not fluctuate with the cell cycle, rather it associates with cyclin $\mathrm{T}$ to form the multiprotein complex, $\mathrm{P}-\mathrm{TEFb}$, which phosphorylates multiple substrates necessary for transcriptional elongation. CDK9 and cyclin T overexpression increased S81 phosphorylation levels in cells. Conversely, siRNA knockdown of CDK9 in LNCaP prostate cancer cells decreased hormone-induced S81 phosphorylation. Treatment of LNCaP cells with two

Published by Bioscientifica Ltd 
different inhibitors of CDK9, 5,6-dichloro-1- $\beta$-D-ribofuranosylbenzimidazole (DRB) and flavopiridol, inhibited S81 phosphorylation and AR-mediated transcription of endogenous genes (Gordon et al. 2010). Flavopiridol is a dose-selective CDK inhibitor, targeting CDK9 at low doses (Chao \& Price 2001), and DRB is a multikinase inhibitor with activity against CDK9. CDK9 inhibition also impaired AR recruitment to prostate-specific antigen (PSA) and TMPRSS2 enhancers (Chen et al. 2012). Furthermore, androgen stimulated phosphorylation of S81 in chemically arrested G1 and S phase cells when CDK1 was inactive, consistent with CDK9 phosphorylating the AR on S81.

Another kinase reported to phosphorylate the AR on S81 is CDK5 (Hsu et al. 2011). CDK5 regulates neuronal development and differentiation and has multiple substrates including proteins, regulating the neuronal cell cytoskeleton and exo- and endocytosis (Dhavan \& Tsai 2001). Recently, Hsu et al. (2011) have correlated the expression of CDK5 protein with AR expression in tumors of prostate cancer patients. In that study, CDK5 was associated with the AR, as shown by co-immunoprecipitation, and phosphorylated the AR on S81 in vitro. However, CDK5 phosphorylation of AR S81 was not observed in other studies (Chen et al. 2006, Gordon et al. 2010). CDK5 overexpression increased AR levels and AR S81 phosphorylation, whereas CDK5 knockdown with siRNA decreased AR levels and S81 phosphorylation (Hsu et al. 2011). This increase in AR levels was paralleled by a decrease in AR ubiquitination. Interestingly, the AR S81A mutant was heavily ubiquitinated when proteasome-dependent degradation was blocked with MG132 (Hsu et al. 2011). These latter data are consistent with the earlier results, demonstrating that proteasome inhibition could block AR degradation resulting from CDK inhibition (Chen et al. 2006). The data linking AR S81 phosphorylation to protein stability is one potential insight into the functional consequence of this phosphorylation event and may explain the correlation with AR S81 phosphorylation and total AR protein levels and CDK1 or CDK5 expression and activity (Chen et al. 2006, Hsu et al. 2011). Phosphorylation on S81 following hormone stimulation may also explain why AR protein levels increase in response to androgen, which is contrary to the hormone-induced protein degradation of other steroid receptors (Gelmann 2002).

\section{Function of $\mathbf{S 8 1}$ phosphorylation}

The functional consequence of S81 phosphorylation on AR transcriptional activity has been examined using a variety of methods. Analysis of S81 phospho-site mutants using reporter assays failed to show significant effects (Chen et al. 2006, 2012, Gioeli \& Paschal 2012) although pharmacologic inhibition of CDK activity did decrease AR transcription of PSA and TMPRSS2 reporters (Chen et al. 2006), suggesting that altering CDK activity may alter AR transcription through effects on CDK-regulated cell-cycle progression. Examination of gene transcription and chromatin binding on endogenous genes has uncovered a function for AR S81 phosphorylation in the regulation of AR transactivation (Gordon et al. 2010, Chen et al. 2012). A survey of eleven known androgen-regulated genes in AR-transfected LHS cells revealed gene-specific changes when S81 was substituted with alanine (Gordon et al. 2010). The majority of AR target genes did not change or showed increased expression; however, TMPRSS2 and ORM1 showed a decrease in transcription when comparing the S81A mutant to WT AR. These data suggest that $\mathbf{8 1}$ phosphorylation is required for regulation of the endogenous AR transcriptional program. Another study used a 'ligand switch' strategy to assess the effect of AR S81 phosphorylation. A W741C mutation was introduced in the LBD, effectively turning the nonsteroidal antiandrogen, bicalutamide, into an AR agonist (Chen et al. 2012). Using this system, loss of $S 81$ phosphorylation also led to a decrease in AR transactivation of endogenous PSA and TMPRSS2 in LNCaP cells.

Multiple studies have demonstrated a role of AR S81 phosphorylation in nuclear localization. Using the ligand switch system, immunofluorescence and biochemical analysis using progressive salt extraction of fractionated cells expressing WT S81A and S81D in the W741C background demonstrated that S81 phosphorylation is required for AR nuclear retention and association with chromatin (Chen et al. 2012). The control W741C mutant and the W741C-S81D mutant show nuclear localization in the absence of bicalutamide and tight association with the insoluble fraction that contains histones. In contrast, the W741C-S81A mutant is excluded from the nucleus at steady state in the absence of bicalutamide and is absent from the insoluble fraction even when bicalutamide is present. Similar observations were made when S81A AR was exogenously expressed in PC3 cells (Hsu et al. 2011). Dephosphorylation of $\mathrm{S} 81$ can also lead to loss of AR nuclear translocation and transcriptional activity (Yang et al. 2007, Wu et al. 2014). Studies have demonstrated that protein phosphatase 2A (PP2A) can bind and dephosphorylate the AR on multiple residues, including S81 (Yang et al. 2007). DAB2IP, a tumor suppressor with GTPase activity, regulates AR S81 phosphorylation

Published by Bioscientifica Ltd. 
in a PP2-dependent manner (Wu et al. 2014) and loss of DAB2IP in mice leads to prostatic intraepithelial neoplasia and increased AR nuclear localization, which is consistent with S81 phosphorylation regulating AR nuclear localization.

ChIP assays of the PSA and TMPRSS2 genes demonstrate that the non-phosphorylatable S81A mutant fails to induce chromatin binding in response to hormone (Chen et al. 2012). Importantly, ChIP experiments of endogenous AR in LNCaP cells showed that phosphorylated S81 AR binds to chromatin. However, phosphorylation on this site is not required for chromatin binding; sequential rounds of ChIP suggest that the non-phosphorylated S81 AR also binds to androgen-response elements (AREs).

The effect of the S81 phosphorylation on growth was tested by stable expression of WT and S81A AR mutant in LHS and LAPC4 cells (Gordon et al. 2010). LHS and LAPC4 cells with increased WT AR expression grew faster than parental cells and cells expressing the S81A AR mutant, indicating that loss of S81 phosphorylation limits cell growth. Similar results were obtained when AR was overexpressed in CWR22Rv1 cells; the S81A mutant decreased growth relative to WT AR (Hsu et al. 2011).

All of these studies follow a similar general paradigm using overexpression, RNAi knockdown, S/A mutant, and pharmacologic inhibitors to interrogate the effect of different CDKs on AR S81 phosphorylation and AR function. Confounding variables include, but are not limited to, differences in cell and AR expression systems used as well as overlapping selectivity of the pharmacologic inhibitors and off-target effects of RNAi approaches. We are left to integrate these studies into a cohesive model that accounts for multiple kinases phosphorylating a single site (Fig. 2). Since S81 is the highest stoichiometric site and loss of S81 phosphorylation inhibits cell growth, there may be a need to have multiple kinases phosphorylate the AR on this site. During transcription, the proximity of P-TEFb to the AR suggests that CDK9 phosphorylates the AR during AR transactivation. This is supported by the finding that $\mathrm{S} 81$ phosphorylated AR on chromatin within 15 min of androgen stimulation (Chen et al. 2012). The role of CDK1 phosphorylating S81 is more elusive, because cells silence most transcription in the G2-M phase; however, some genes remain transcriptionally active during mitosis. Thus, it is plausible that CDK1 phosphorylation of S81 may regulate AR activity on a subset of genes as was observed with the S81A mutant in one study (Gordon et al. 2010). One attractive hypothesis is that CDK1 phosphorylation on $\mathrm{S} 81$ is critical for the initiation of gene

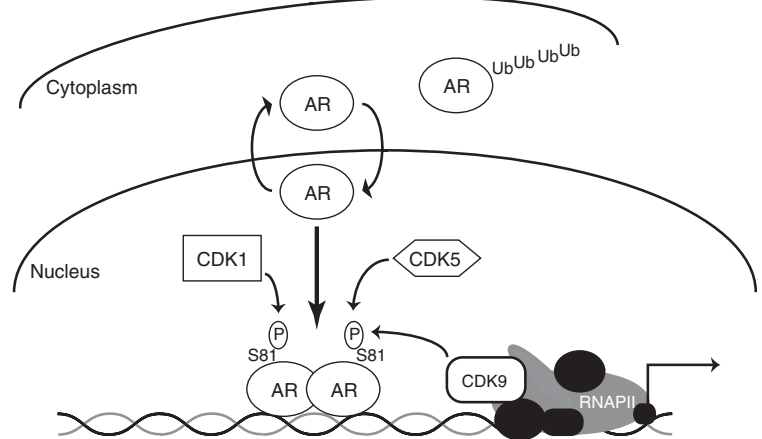

Figure 2

AR S81 phosphorylation regulates AR transcriptional activity, nuclear retention, protein levels, and growth. $\mathrm{S} 81$ is phosphorylated by CDK1, $C D K 5$, and CDK9 leading to increased AR transcriptional activity, $A R$ retention in the nucleus, and cell growth. The lack of $A R$ phosphorylation on S81 leads to cytoplasmic localization, AR ubiquitination, and AR degradation.

transcription following mitosis. What role CDK5 plays in the regulation of $\mathrm{S} 81$ phosphorylation in the context of CDK1 and CDK9 phosphorylation of this site is unclear. One hypothesis suggested that CDK5 phosphorylation of AR S81 causes AR nuclear localization and stabilization (Hsu et al. 2011). Clearly, further studies are required to determine the biological consequence of $\mathrm{S} 81$ by the different CDKs.

\section{S213, S791, and T850 phosphorylation}

Studies suggest that AR S213 is the target of several kinases (Fig. 3), at least two of which, Akt and PIM1, are known to phosphorylate S213 with different functional consequences (Wen et al. 2000, Lin et al. 2001, 2003, Taneja et al. 2005, Palazzolo et al. 2007, Ha et al. 2012, Kasina \& Macoska 2012, Linn et al. 2012, Varisli et al. 2012). Moreover, Aktdependent AR S213 phosphorylation is regulated by several signaling pathways (Wen et al. 2000, Kasina \& Macoska 2012, Varisli et al. 2012). Both Akt and PIM1 play important roles in prostate cancer progression. Akt signaling is frequently activated in prostate cancer through a variety of mechanisms including hetero- and homozygous loss of PTEN and mutations in the $1110 \alpha$ catalytic subunit of PI3K (Shen \& Abate-Shen 2007, Sarker et al. 2009). PIM1 shares substrates with Akt beyond the AR, including $\mathrm{BAD}$ and MDM2 (Aho et al. 2004, Wood et al. 2009). PIM1 expression may have prognostic value for prostate cancer (Shah et al. 2008). A number of studies have shown that PIM1 can cooperate with c-myc in oncogenic transformation studies and c-myc is implicated in prostate cancer progression, including being activated by the TMPRSS2-ERK

Published by Bioscientifica Ltd. 


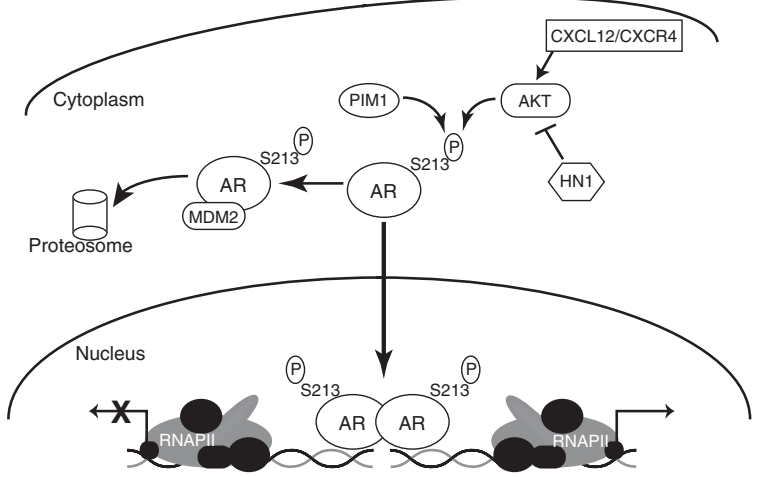

Figure 3

AR S213 phosphorylation results in different functional outcomes including effects on AR transactivation, AR stability, and prostate cancer cell growth and survival. S213 phosphorylation regulates AR transactivation, stability, and nuclear translocation in a cell context-dependent manner. This schematic does not discriminate between PIM1 isoforms. PIM1S, but not PIM1L, increases AR degradation by promoting AR association with MDM2 in an S213-dependent manner. PIM1S up-regulates transcription of proliferative genes and down-regulates transcription of the AR-regulated differentiation genes.

fusion (Zippo et al. 2007, Sun et al. 2008, Zhang et al. 2008, Wang et al. 2010). PIM1 and Akt are also implicated in prostate cancer with a recent report suggesting that PIM1 is critical for Akt-driven upregulation of RTK expression through cap-independent translation (Cen et al. 2013). Akt and PIM1-dependent AR S213 phosphorylation have revealed different functional consequences depending on the context, including effects on AR stability, AR transactivation, and prostate cancer cell growth.

\section{Akt phosphorylates the AR on S213 and S791}

Several studies demonstrated that Akt directly binds and phosphorylates the AR on serines 213 and 791 (Wen et al. 2000, Lin et al. 2001, 2003, Taneja et al. 2005). Co-immunoprecipitation experiments revealed that activated Akt specifically associated with endogenous AR in LNCaP cells (Wen et al. 2000, Lin et al. 2001). Furthermore, Akt was able to phosphorylate the AR on serines 213 and 791 in an in vitro kinase assay (Wen et al. 2000).

Studies on the effect of the Akt-mediated AR serines 213 and 791 phosphorylation on AR transcription have yielded conflicting results demonstrating either repression (Lin et al. 2001, Taneja et al. 2005, Palazzolo et al. 2007) or activation of AR function (Wen et al. 2000). Akt repressed AR transactivation in a reporter assay in AR-negative castration-resistant prostate cancer DU145 cells when the AR was exogenously expressed (Lin et al. 2001). In transfected cells, AR phosphomimetic mutants at the
Akt consensus sites repressed transactivation of a reporter in response to dihydrotestosterone (DHT), decreased hormone-mediated AR protein stabilization, and abrogated nuclear translocation (Palazzolo et al. 2007). However, in the androgen-dependent prostate cancer LNCaP cell line, Akt phosphorylation activated the PSA reporter and promoted cell survival (Wen et al. 2000, Lin et al. 2001). These differential effects of Akt-mediated AR S213 phosphorylation on AR function could be attributed to cell context. Indeed, Akt was shown to regulate AR activity in a cell passage number-dependent manner in LNCaP cells (Lin et al. 2003). The data suggest that modifiers of AR S213 function exist in different contexts, which may be related to disease progression.

\section{CXCR regulation of S213}

AR was also phosphorylated on S213 in response to the activation of the G-protein-coupled receptor, chemokine receptor 4 (CXCR4), by its ligand CXCL12 in an androgenindependent manner (Kasina \& Macoska 2012). At least one mechanism of AR activation by CXCL12/CXCR4 may be through PI3K/Akt-dependent AR S213 phosphorylation. Experiments with pharmacological inhibitors of MAPK and PI3K pathways revealed that phosphorylation of SRC1 by MAPK on threonine was required for ligandindependent activation of the AR and that AR S213 phosphorylation is PI3K-dependent. Moreover, treatment with Src and PKC inhibitors showed that multiple kinases are involved in CXCL12/CXCR4-mediated activation of the AR. Although CXCL12/CXCR4-mediated AR transactivation was relatively weak compared with activation by androgen, it serves as an example of how AR activity can be maintained in the absence of androgen.

\section{HN1 regulation of S213 phosphorylation}

Interestingly, the AR-regulated gene, hematological and neurological expressed 1 (HN1), has been shown to negatively regulate AR signaling and androgen-regulated growth of prostate cancer cells (Varisli et al. 2012). HN1 regulated AR steady state levels by inhibiting PI3K-dependent Akt phosphorylation on S473. HN1 overexpression in LNCaP cells results in AR S213 dephosphorylation and a decrease in AR levels. This decrease in AR expression could be restored by the proteasomal inhibitor, MG132. The converse was also observed; HN1 knockdown resulted in increased AR protein expression and AR nuclear translocation. This work suggests a

Published by Bioscientifica Ltd. 
negative feedback loop between HN1 and the AR involving AR S213 phosphorylation.

\section{PIM1 phosphorylates S213}

AR S213 was also shown to be a target for PIM1 kinase (Linn et al. 2012). PIM1 has two isoforms, $44 \mathrm{kDa} P I M 1 L$ and $33 \mathrm{kDa}$ PIM1S (Saris et al. 1991), both of which can directly interact with the AR and phosphorylate it at different residues, namely S213 and T850. AR S213 was phosphorylated by both PIM1 isoforms in in vitro kinase assays and when exogenously expressed in cells. However, only PIM1L was able to phosphorylate T850 effectively (Linn et al. 2012). Data from another group supports the notion that AR is phosphorylated on S213 by PIM1 in a ligand-independent manner. The $33 \mathrm{kDa}$ isoform of PIM1 phosphorylated the AR on S213 in cells and in vitro (Ha et al. 2012).

Studies show that PIM1-mediated phosphorylation at S213 and T850 leads to the recruitment of different ubiquitin E3 ligases that have different effects on AR stability (Linn et al. 2012). Co-transfection of PIM1 kinase isoforms and the AR, as well as the S213A mutant into 293T cells, revealed that AR phosphorylation on S213 by PIM1S, but not PIM1L, decreased the AR half-life, and the phosphomimetic. The T850D mutant was resistant to this S213-dependent PIM1S-induced deregulation. In chemically arrested LNCaP cells, expression of both PIM1 isoforms was increased in the $\mathrm{G} 2$ and $\mathrm{M}$ phases of the cell cycle, which correlated with AR phosphorylation on S213 and T850 (Lin et al. 2001). Another study, however, reported that S213 did not increase during the time-course of nocodazole arrest (Chen et al. 2012). Interestingly, when endogenous AR was knocked down and the WT AR and S213A mutant were reexpressed in LNCaP cells, the S213A mutant was more stable than the WT AR in cells synchronized in mitosis (Lin et al. 2001). Co-immunoprecipitation experiments were used to determine the differential effects of S213 and T850 phosphorylation on AR stability. PIM1S phosphorylation on S213 enhanced the interaction of the AR with MDM2 leading to AR proteolysis, while PIM1L phosphorylation on T850 enhanced the interaction of the AR with RNF6, which does not cause AR destabilization (Xu et al. 2009). These data suggest that PIM1 isoforms have differential effects on AR protein stability with the net effect depending on both S213 and T850 AR phosphorylation.

PIM1L, but not the PIM1S isoform, could enhance AR transcriptional activity in a reporter assay under low serum conditions and mutations of either S213 or T850 abrogated PIM1L-induced increase in AR transcriptional activity. In LNCaP cells infected with lentiviruses encoding PIM1 kinases, PIM1L activated expression of endogenous AR target genes in a promoter context-dependent manner (Linn et al. 2012). Another group, however, showed that AR S213 phosphorylation by PIM1S repressed AR function (Ha et al. 2012). Although the reporter assay and cell line systems used in these studies are similar, the experimental design, namely androgen concentrations, was different. In the former study, in which PIM1S had no effect on AR transcriptional activity in a reporter assay, the experiments were performed under low androgen conditions (Linn et al. 2012), whereas in the later study using a high concentration $(10 \mathrm{~nm})$ of synthetic androgen R1881, PIM1S-mediated AR S213 phosphorylation repressed AR-dependent transcription (Ha et al. 2012). WT AR, but not S213A-expressing cells, showed decreased transcription of an androgen-responsive reporter gene. Furthermore, in this study induction of endogenously expressed PSA and Nkx3.1 was reduced in response to hormone in LNCaP cells overexpressing PIM1S. In addition, overexpression of PIM1 resulted in activation of $\mathrm{AR}$ and upregulation of genes implicated in cell proliferation, including cyclin A1, IL6, and caveolin 2 .

Overexpression of PIM1 kinases in LNCaP cells resulted in an increase in cell growth under low androgen conditions (Linn et al. 2012). Furthermore, replacement of endogenous AR with the codon-switched AR S213 or T850 abrogated the increase in PIM1-promoted cell proliferation. These experiments suggested that phosphorylation of AR on S213 and T850 could sensitize prostate cancer cells to low androgens.

Since Akt and PIM1 are potential drivers of prostate cancer, understanding how these kinases regulate AR function through S213 phosphorylation is an important question. The data described above suggests that the function of S213 phosphorylation is context dependent and will be different depending on which kinase (and kinase isoform) phosphorylates this residue. Determining the physiologic and disease context of the effect of S213 phosphorylation remains an open question.

\section{T282 and S293 phosphorylation}

In vitro kinase assays showed that the $\mathrm{AR}$ can be phosphorylated by the serine/threonine kinase Aurora-A (Shu et al. 2010). Sequence analysis predicted that the N-terminal T282 and S293 were two potential Aurora-A phosphorylation sites. These two sites were confirmed as Aurora-A targets in vitro and in vivo. While T282 and S293

Published by Bioscientifica Ltd 
are not induced by androgen, they are required for maximal AR transactivation in cells exposed to androgen. Co-immunoprecipitation carried out in castrationresistant cells derived from $\mathrm{LNCaP}$ demonstrated that the AR directly associated with Aurora-A. In reporter assays using a synthetic ARE promoter, the double T282A/S293A mutant decreased the Aurora-A-induced AR transcriptional activity in the presence or absence of androgen compared with WT AR. This suggests that the phosphorylation of T282 and S293 was not only required for the activation of AR induced by Aurora-A but also required for the regulation of the response to androgen. T282/S293 phosphorylation by Aurora-A enhanced both AR DNA binding and LNCaP cell growth. Aurora-A expression is elevated and the gene is amplified in prostate cancers associated with high PSA, late stage, high Gleason score, and poor prognosis (Buschhorn et al. 2005, Furukawa et al. 2007, Beltran et al. 2011, Mosquera et al. 2013). These data suggest that the phosphorylation of T282 and S293 resulting from the elevated expression of Aurora-A in prostate cancer could contribute to castration resistance (Shu et al. 2010). How this information can be leveraged to improve prostate cancer therapies, particularly radiation therapy, which is the standard of care for locally advanced prostate cancer, has not yet been determined.

\section{S308 phosphorylation}

The AR is phosphorylated on $\mathrm{S} 308$ by $\mathrm{CDK} 11^{\mathrm{P} 58}$, the isoform of CDK11 that is specifically expressed in G2-M. Sequential co-immunoprecipitation using whole-cell lysates from transfected cells revealed that the AR forms a ternary complex with $\mathrm{CDK} 11^{\mathrm{P} 58} /$ cyclin D3 in mammalian cells. CDK11 ${ }^{\mathrm{P} 58}$ autophosphorylation is necessary for its kinase activity and kinase-dependent effect on AR function (Chi et al. 2011). CDK11 ${ }^{\mathrm{P} 58}$ was able to phosphorylate the $\mathrm{N}$-terminal portion of the AR in an in vitro kinase assay. Using Ser to Ala N-terminal AR mutants as substrates in kinase assays, only S308A mutants showed reduced phosphorylation (Zong et al. 2007).

Importantly, phosphorylation of the AR on S308 by CDK11 ${ }^{\mathrm{P} 58}$ repressed its function and proliferation of prostate cancer cells. Exogenous expression of cyclin D3 and $\mathrm{CDK} 11^{\mathrm{P} 58}$ inhibited AR-dependent transcription in reporter assays using several cell lines, including prostate cancer cell lines LNCaP and PC3. Furthermore, overexpression of either $\mathrm{CDK} 11^{\mathrm{P} 58}$ or cyclin D3 or the combination of these two proteins repressed PSA mRNA levels in LNCaP cells. In agreement with this data, siRNA against $\mathrm{CDK}_{11}{ }^{\mathrm{P} 58}$ or cyclin D3 abrogated PSA mRNA repression. Moreover, overexpression of $\mathrm{CDK} 11^{\mathrm{P} 58}$ decreased proliferation in LNCaP cells detected by BrdU incorporation. The S308A mutant failed to repress AR transcriptional activity in reporter assays when co-transfected with cyclin D3/CDK11 ${ }^{\mathrm{P} 58}$ (Zong et al. 2007). These data suggest that cyclin D3/CDK11 P58 represses AR transcriptional activity through phosphorylation on S308. Consistent with these observations, cytoplasmic cyclin D3 protein expression levels were decreased in primary prostate cancers with increasing Gleason score and inversely correlated with cell proliferation by Ki-67 staining (Olshavsky et al. 2008). How, or whether AR S308 phosphorylation relates to changes in cyclin D3 levels in patient samples has not yet been determined.

\section{S405 phosphorylation}

A novel AR phosphorylation site was discovered by genomic DNA sequencing of a Caucasian male with androgen insensitivity syndrome, a disorder that results in the incomplete development of the external genitalia of 46,XY genetic males (Lagarde et al. 2012). The S405 phospho-site was created by a missense mutation in exon 1 of the AR, which resulted in the substitution of arginine for serine at amino acid position 405 . The R405S mutation reduced AR transcriptional activity in luciferase assays in CV1 cells expressing WT AR or the R405S mutant. Western blot analysis of COS- 1 cells transfected with WT $\mathrm{AR}, \mathrm{R} 405 \mathrm{~S}$, or select AR subdomains in the presence or absence of phosphatase inhibitors, suggesting that the loss of function due to the R405S mutation was associated with the creation of the S405 phosphorylation site. Transcriptional activity in cells expressing the R405A mutant was not affected, supporting the negative effects of phosphoS405 on transcription. The R405S mutation is located in the N-terminal AF1 domain, 27 residues upstream from the WXXLF motif, which is required for transcriptional activation associated with the AR co-regulators primatespecific melanoma antigen-A11 (MAGE-11) and p300 (Lagarde et al. 2012). AR transactivation depends on interactions with co-regulators and the interdomain $\mathrm{AR}$ $\mathrm{NH}_{2^{-}}$and carboxyl-terminal (N/C) interaction between the N-terminal FXXLF motif and LBD AF2, which is stabilized by androgen (He et al. 2004, Heemers \& Tindall 2007). MAGE-11 binds the FXXLF motif and functions synergistically with the co-regulators and transcription factors to regulate the AR N/C interaction (Bai et al. 2005). Mutation of the FXXLF motif inhibits AR transcriptional activity by disrupting the AR N/C

Published by Bioscientifica Ltd. 
interdomain interaction. Reporter assays using full-length AR and fragments revealed that the WXXLF motif was also required for MAGE-11-induced AR transactivation, because MAGE-11 failed to elicit a transcriptional response in cells expressing fragments lacking the WXXLF motif (Lagarde et al. 2012). Previous studies where the histone acetyltransferase p300 was found to be silenced by siRNA determined that p300 was required in AR transactivation associated with the androgen-dependent AR N/C interaction (Askew et al. 2010). p300 directly associated with MAGE-11, which appeared to be a required factor in the AR transcriptional response to p300. Together, these data suggest the hypothesis that the deleterious effects on transcription resulting from the phosphorylation of S405 may be related to the proximity of this phospho-site to the WXXLF motif, thereby interfering with the ability of MAGE-11 to recruit the coactivator p300 to enhance transcription associated with the AR N/C interaction. Also in close proximity to the WXXLF motif is the $\mathrm{S} 424$ phosphorylation site. Little is known about $\mathrm{AR}$ S424 phosphorylation other than it being induced by androgen (Gioeli et al. 2002). It is not known if phosphorylation of S424 has any effect on MAGE-11 association with the AR or if it influences AR biology in the context of the R405S mutation.

\section{S515 and S578 phosphorylation}

Another AR phosphorylation site associated with multiple kinases is S515 with both CDK7 and MAPK reported to phosphorylate this site. CDK7 is an essential component of the general transcription factor, TFIIH, which activates RNAPII initiating transcription (Harper \& Elledge 1998). Purified recombinant TFIIH phosphorylated the AR in vitro and this phosphorylation was reduced when a S515A mutant was used as a substrate, suggesting that CDK7 phosphorylates the AR on S515 (Chymkowitch et al. 2011). The evidence for MAPK phosphorylation of S515 is indirect but, in aggregate, compelling. Following up on data showing that epidermal growth factor (EGF) signaling increased AR transactivation and prostate cancer cell growth (Mellinghoff et al. 2002, Gregory et al. 2004), mutational analysis of candidate AR serine and threonine phosphorylation sites led to the identification of S515 as the site of AR phosphorylation in response to EGF treatment (Ponguta et al. 2008). Using mobility shifts on SDS-PAGE as a readout of phosphorylation, the S515A mutant and the MEK1/2/5 inhibitor, UO126, both prevented the EGF-induced mobility shift of an AR fragment consisting of amino acids 507-660, further suggesting that MAPK phosphorylates AR S515. These results were consistent with an earlier study showing that MAPK phosphorylates an N-terminal fragment of the AR containing S515 (Yeh et al. 1999). MAPK signaling is elevated as prostate cancer progresses to castration resistance and inhibiting MAPK can be effective therapeutically when targeted along with other signaling pathways (Gioeli et al. 1999, 2011, Kinkade et al. 2008). Not yet known is what role MAPK phosphorylation of AR S515 plays in cancer progression or therapeutic response to MAPK inhibition.

Interestingly, AR S515 phosphorylation is co-regulated with S578 phosphorylation by EGF signaling (Ponguta et al. 2008). The evidence for AR phosphorylation on S578 is from immunoreactivity with an antiphospho-S578 antibody and in vitro kinase assays with a purified, catalytically active PKC subunit. Phosphorylation of the S578A mutant was reduced when compared with WT AR in EGF-stimulated cells consistent with S578 phosphorylation by PKC. Exogenous expression of the S578A mutant led to an increase in the mobility shift, consistent with an increase in S515 phosphorylation (Ponguta et al. 2008) and indicating that phosphorylation on S515 is maximal when S578 is not phosphorylated. PAK6 is also an AR S578 kinase (Liu et al. 2013). PAK6 phosphorylation on S578 regulates AR interaction with MDM2 and proteasomal-dependent degradation. In vitro kinase assays using purified proteins and S/A mutants suggests that PAK6 can phosphorylate S578. Exogenous expression of AR and PAK in HEK293 cells revealed that PAK6 kinase activity was required for AR S578 phosphorylation and that $\mathrm{S} 578$ phosphorylation was required for association with MDM2 and subsequent AR ubiquitination and degradation (Liu et al. 2013).

\section{Function of S515 phosphorylation}

Loss of S515 phosphorylation reduces AR transactivation; the $5515 \mathrm{~A}$ mutant had reduced transcriptional activity in assays using a PSA reporter (Ponguta et al. 2008, Chymkowitch et al. 2011). The S578A mutant reduced AR transactivation more than the S515A mutant and the double mutant S515/578A had virtually no transcriptional activity (Ponguta et al. 2008). Since loss of S578 phosphorylation increases S515 phosphorylation, it seems that the loss of phosphorylation on S578 and subsequent effects on transcription are dominant to S515 phosphorylation. AR phosphorylation on S578 may regulate transcription through affecting AR nuclear localization and association with

Published by Bioscientifica Ltd 
transcriptional coactivators. Loss of S578 (S578A) led to increased nuclear localization and, by co-immunoprecipitation studies, association with the Ku70/80 regulatory subunits of DNA-PK. The strong association of the S578A mutant with $\mathrm{Ku} 70 / 80$ and nuclear retention may disrupt the rapid transient DNA binding and nuclear-cytoplasmic shuttling required for steroid receptor transactivation (McNally et al. 2000).

AR S515 phosphorylation may also regulate protein turnover (Chymkowitch et al. 2011). Prolonged AR protein turnover was observed in pulse-chase experiments using xeroderma pigmentosum cells carrying a mutation in a TFIIH subunit, leading to deregulation of CDK7 or cells expressing a S515A mutant AR. The increase in AR protein stability corresponded with a change in the recruitment of E3 ubiquitin ligase proteins at the PSA promoter. WT AR recruits the E3 ligase MDM2 to the PSA promoter. Loss of S515 phosphorylation by mutation to alanine leads to the recruitment of the E3 ligase, CHIP, which replaces MDM2. Both MDM2 and CHIP ubiquitinate the AR; however, S515 phosphorylation by CDK7 may specify which E3 ligase is used to modify the AR activity.

\section{S650 phosphorylation}

AR phosphorylation on $\mathrm{S} 650$ by stress kinases inhibits AR transcriptional activity by promoting its nuclear export (Gioeli et al. 2006). Evidence suggests that stress kinases MKK4/JNK and MKK6/p38 directly phosphorylate AR on S650. First, exogenous expression of MAPKK 4 (MKK4) and JNK1 or MKK6 and p38 $\alpha$ along with the AR in COS cells leads to a robust increase in AR S650 phosphorylation over basal levels. Second, treatment with pharmacological inhibitors, either to p38 or JNK1, dramatically diminished endogenous AR S650 phosphorylation in LNCaP cells. Furthermore, JNK1 and p38 $\alpha$ were able to directly phosphorylate AR on S650 in vitro. Importantly, stress kinases MKK4 and MKK6 negatively regulate AR-dependent transcription. Inhibiting MKK4 and MKK6 by siRNA in LNCaP cells leads to an increase in basal, as well as DHT-stimulated, PSA mRNA levels. The increase in PSA mRNA expression was abrogated by either the antiandrogen bicalutamide or AR siRNA, demonstrating that the stress kinase-mediated effect on the PSA expression is dependent on the AR. S650 is located in the Hinge region in proximity to the DBD nuclear export signal. Therefore, its role in nuclear-cytoplasmic shuttling was assessed using the heterokaryon shuttling assay. Using this assay, experiments with phospho-S650 mutants and pharmacological inhibition of p38 and JNK revealed that S650 phosphorylation was required for nuclear export, and stress kinase signaling regulates export of the AR. Taken together, these data suggest that MKK4/JNK and MKK6/p38 directly phosphorylate the AR on S650 and negatively regulate $A R$ transcription by facilitating $A R$ nuclear export (Gioeli et al. 2006). This is consistent with JNK signaling negatively regulating prostate cancer in PTEN null mice (Hübner et al. 2012). What role AR S650 phosphorylation plays in this antagonism has not been determined.

\section{AR tyrosine phosphorylation}

\section{Y267 and Y363 phosphorylation by Ack}

Multiple tyrosine residues on the AR can be phosphorylated (Fig. 4; Guo et al. 2006, Mahajan et al. 2007). Deletion analysis with truncated AR proteins, mass spectrometry, and immunoblot analysis of phosphorylation site point mutants identified by an artificial neural network-based method expressed in 293T cells determined that Y267 and Y363 are phosphorylated by Ack (Mahajan et al. 2007). Various ligands can induce specific tyrosine kinases to phosphorylate distinct tyrosine residues on the AR (Liu et al. 2010). Tyr 267 is phosphorylated by Ack in response to EGF, Heregulin, and Gas6 (Mer receptor ligand). Expression of the Y267F and Y363F mutants decreased gene transcription of, and DNA binding to the

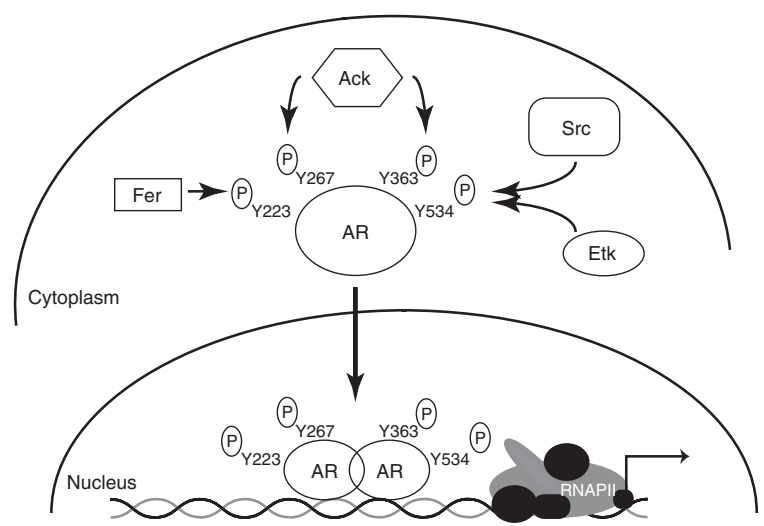

Figure 4

AR tyrosine phosphorylation regulates gene transcription, growth, and protein stability. Y223 phosphorylation by Fer results in the formation of Fer-AR complex in the nucleus and activation of gene transcription. Ack phosphorylates Y267 and Y363 to enhance transcription of AR target genes (i.e. PSA and ATM) and cellular growth. The phosphorylation of Y534 by Src and Etk leads to increased gene transcription, cell growth, and AR stabilization.

Published by Bioscientifica Ltd. 
PSA enhancer. Furthermore, mutation of Y267 blocked the castration-resistant growth of prostate cancer xenografts, implicating Y267 as a critical phosphorylation site for castration-resistant AR transactivation and tumorigenesis. Western blotting of primary prostate cancer specimen lysates revealed increased AR tyrosine phosphorylation associated with active Ack in human castration-resistant prostate cancer tumors but not in normal prostate tissue (Mahajan et al. 2007). ChIP-on-chip analysis of endogenous AR in EGF-stimulated LAPC4 cells showed that the AR was specifically recruited to the ATM enhancer when Y267 was phosphorylated (Mahajan et al. 2012). In vitro reporter assays confirmed that the phosphorylation of Y267 promoted the recruitment of the AR to the ATM enhancer and increased AR transactivation. EGF-treated LAPC4 and LNCaP cells showed a significant increase in phosphorylation of Y267, and this correlated with increased ATM mRNA and ATM protein levels. DHT did not promote any changes in ATM mRNA levels nor DNA binding to the ATM enhancer. These events were blocked in the presence of the Ack1 inhibitor AIM-100, indicating that the phosphorylation of Y267 is required for AR binding to the ATM enhancer and the subsequent increase in ATM gene transcription. Data from clonogenic survival assays and xenograft tumor growth studies suggest that the inhibition of Y267 phosphorylation with AIM-100 resensitizes CRPC cells to radiotherapy. These data identify a novel signaling pathway, where the phosphorylation of Y267 plays a critical role in castration-resistant prostate cancer resistance to radiation therapy.

\section{Y534 phosphorylation by Src and Etk}

AR Y534 was identified by mass spectrometric analysis as a major Src kinase phosphorylation site. Y534 has been shown to be phosphorylated by Src in the presence of EGF, IL6, and Bombesin (Guo et al. 2006). Mutation of this tyrosine to phenylalanine decreased AR transcriptional activity in reporter assays in response to EGF and low doses of hormone. Expression of the AR Y534F mutant under hormone-depleted conditions in CWR22-Rv1 and LNCaP cell lines and tumor xenografts resulted in diminished growth when compared with WT AR-expressing cells. Using phospho-specific antisera to Y534, immunohistochemistry (IHC) analysis showed a positive correlation between Y534 phosphorylation during prostate cancer progression and Src activity (Guo et al. 2006). Interestingly, the phosphorylation of Y534 was also strongly correlated with the nonreceptor tyrosine kinase epithelial and endothelial tyrosine kinase (Etk) expression in mouse and human prostate tumors (Dai et al. 2010), suggesting that Y534 phosphorylation levels may partly be attributed to Etk. Co-transfection experiments in COS-1 cells using WT AR and WT Etk, kinase-dead Etk, or constitutively active Src as a positive control showed that WT Etk induced AR tyrosine phosphorylation but not to the magnitude induced by Src. Under castration conditions, the up-regulation of Etk resulted in increased Y534 phosphorylation and stabilization of the AR, thereby linking Y534 phosphorylation to AR stability (Dai et al. 2010). Introducing the $\mathrm{Y} 534 \mathrm{~F}$ mutant in LNCaP cells led to increased AR degradation (DaSilva et al. 2009). Mutational studies indicate that Etk also phosphorylates Y551 and Y552 (Dai et al. 2010). Data from glutathione $S$-transferase pull-down experiments suggest that these phosphotyrosine residues may promote the interaction between the AR and the SH2 domain of Etk. Furthermore, the Etk-induced phosphorylation of Y534 is dependent on the phosphorylation of Y551/552. Therefore, the relative contribution that Src and Etk make to the phosphorylation of the AR may depend on the cell context and stimuli.

Unfortunately, recent phase III clinical trial data have shown that dasatinib, a multikinase inhibitor with activity against Src family kinases, failed to improve survival in men with metastatic castration-resistant prostate cancer (Araujo et al. 2013). It would be interesting to know if dasatinib treatment affected AR Y534 phosphorylation in these patients. If dasatinib did not alter AR Y534 phosphorylation, then the therapeutic benefit of inhibiting the phosphorylation of AR Y534 through Src family kinases remains conceptual and untested.

\section{Y223 phosphorylation}

Gain and loss of function studies show that IL6 promotes the phosphorylation of AR tyrosine residues by the tyrosine kinase Fer in LNCaP and AR-expressing PC3 cells (Rocha et al. 2013). In vitro kinase assays indicate that Fer phosphorylates Y223 in the presence of IL6, leading to the formation of Fer-AR complexes in the nucleus, and enhances PSA transcription in LNCaP and C42 cells exposed to IL6.

\section{In situ phospho-AR staining of human samples}

There is a paucity of information on the levels of $A R$ phosphorylation in patient samples. Few studies have been done although this is an outstanding question of significant importance in the field. The majority of AR phospho-specific antibodies have not been rigorously

Published by Bioscientifica Ltd. 
validated for in situ use, and the selectivity of phosphoserine antibodies is notoriously problematic for studies in tissues. Phospho-tyrosine antibodies are typically more selective and thus are more likely to be suitable for in situ experiments. The first study examining phospho-AR in tissues evaluated pS213 in human fetal urogenital sinus epithelial cells (Taneja et al. 2005). When elevated androgen levels and activated AKT were both present, phospho-S213 staining was detected. In this study, S213 was not phosphorylated in dividing cells, as determined by Ki-67 staining, and there was no S213 phosphorylation in stromal cells although stromal cells were strongly AR positive. This latter observation is an important control, such that when considered with the selectivity of the antibody on western blot analysis of cell lysate and peptide-blocking experiments, suggests that the phosphoS213 antibody used in this study is highly selective. In the adult human normal prostate, staining for phospho-S213 was heterogeneous, whereas total AR staining was more homogeneous. These results suggested that S213 phosphorylation occurs in a cell-type and developmental-specific manner (Taneja et al. 2005).

The first study to examine AR phosphorylation in prostate cancer evaluated AR Y534 phosphorylation (Guo et al. 2006). Y534 phosphorylation was significantly increased in castration-resistant prostate tumors as compared with hormone naïve tumors. IHC analysis of tissue micro arrays showed that the mean intensity of immunostaining for phospho-Y534 was higher in castration-resistant disease. The phospho-Y534 signal correlated with both Src and Etk levels in patient samples (Guo et al. 2006, Dai et al. 2010). The selectivity of the antibody used in this study was rigorously evaluated. Western blotting of whole-cell lysates of stimulated and unstimulated prostate cancer cells, peptide-blocking as well as IHC and western blots of WT and the phospho-null mutant Y534F, all demonstrated phospho-Y534 antibody selectivity (Guo et al. 2006).

Phosphorylation of Y267 was examined by IHC staining of a prostate tumor microarray that was also stained for ATM, which associates with Y267 phosphorylated AR (Mahajan et al. 2012). A significant positive correlation was observed between the levels of Y267 phosphorylation and ATM expression and the severity of disease progression, suggesting the clinical importance of Y267 phosphorylation (Mahajan et al. 2012). The antibody used in this latter study was validated by western blotting of lysate from agonist-stimulated cells and from cells overexpressing Ack kinase (Mahajan et al. 2010). In this study, AR Y267 phosphorylation correlated with Ack Y287 phosphorylation, consistent with elevated Ack activity leading to an increase in AR Y267 phosphorylation.

Other studies using an anti-phospho-S213 antibody have implicated S213 phosphorylation in prostate cancer progression. Studies have shown that phospho-S213 staining increases as prostate cancer progresses from hormone naïve to castration resistance (McCall et al. 2008, Ha et al. 2012, Zellweger et al. 2013). One of these studies describes antibody validation, using calf intestinal alkaline phosphatase treatment of parallel slides (McCall et al. 2008) and another shows agonist-stimulated or inhibitor regulation of S213 phosphorylation by western blotting (Ha et al. 2012). These studies showed that phosphorylation of S213 was associated with poor overall survival (McCall et al. 2008, Ha et al. 2012, Zellweger et al. 2013), although in one study this association was restricted to cytoplasmic phospho-S213 staining (Ha et al. 2012). Nuclear AR S213 phosphorylation was significantly increased in cases with high Gleason scores, even though nuclear S213 phosphorylation was not predictive of disease outcome (Ha et al. 2012). In general, these studies parallel observations of total AR levels as prostate cancer progresses from castration sensitive to castration resistant (Linja et al. 2001), but more specifically that AR S213 phosphorylation increases as prostate cancer progresses to castration resistance.

AR phosphorylation has also been examined in breast cancer specimens (Ren et al. 2013). Using the previously validated anti-phospho-S213 AR antibody (Taneja et al. 2005), this study shows elevated phosphorylation of S213 in breast cancers relative to benign breast tissue (Ren et al. 2013). S213 phosphorylation was elevated in invasive ductal carcinoma, metastatic breast cancer, and estrogen receptor (ER)-negative breast cancers. AR S650 phosphorylation was also evaluated in breast cancer using an antibody validated by western blotting of WT and S650A AR, PMA and hormone-stimulated AR, phosphatase treated $\mathrm{AR}$, and peptide-blocking experiments of IHC samples (Ren et al. 2013, S Logan, personal communication 2013). AR S650 phosphorylation overall was decreased in breast cancers, but phosphorylation of S650 was elevated in select circumstances such as ER-negative breast cancers and breast cancers with distant metastasis. This study suggests that AR phosphorylation may play a role in breast cancer development and progression, which is consistent with the emerging role of the AR in breast cancer (Hickey et al. 2012).

AR phosphorylation on serines $81,94,308,515,650$, and 791 in prostate cancer patient specimens has been evaluated (McCall et al. 2013, Willder et al. 2013). In these

Published by Bioscientifica Ltd. 
studies, correlations with clinical parameters, including patient outcome, were linked to AR phosphorylation at different sites. A confounding variable in these studies is that antibody selectivity was established using peptideblocking experiments. While this is an important step for validating antibodies for IHC, in isolation it does not demonstrate specificity (Mandell et al. 1998, Al-Dhaheri \& Rowan 2006, Brumbaugh et al. 2011). The concern is that pre-absorption with phosphorylated peptide can block all immunoreactivity, including nonspecific antibody staining. Nonetheless, these studies generate interesting and exciting hypotheses about the role of AR phosphorylation in prostate cancer progression, both mechanistically and prognostically.

\section{Summary}

The AR integrates input from hormone binding with the cell signaling network through post-translational modifications including phosphorylation. There is still much to learn about AR phosphorylation. For many sites, the proximal kinase remains unknown and the biological context of AR phosphorylation in both normal physiology and disease remains an important unanswered question. Furthermore, little is known about the potential interplay between different AR phosphorylation sites. In addition to phosphorylation, the AR is acetylated, sumoylated, ubiquitinated, and methylated. How the multitude of AR post-translational modifications interact to regulate AR function will keep scientists busy for decades to come.

\section{Declaration of interest}

The authors declare that there is no conflict of interest that could be perceived as prejudicing the impartiality of the review.

\section{Funding}

The authors were supported by funding from the National Cancer Institute (R01 CA124706, D Gioeli), the Paul Mellon Urologic Cancer Institute (D Gioeli), and a Farrow Fellowship (Y Koryakina).

\section{Acknowledgements}

The authors would like to thank Dr Nikki Watson for critical reading of the manuscript.

\section{References}

Aarnisalo P, Palvimo JJ \& Janne OA 1998 CREB-binding protein in androgen receptor-mediated signaling. PNAS 95 2122-2127. (doi:10.1073/pnas.95.5.2122)
Aho TL, Sandholm J, Peltola KJ, Mankonen HP, Lilly M \& Koskinen PJ 2004 Pim-1 kinase promotes inactivation of the pro-apoptotic Bad protein by phosphorylating it on the Ser112 gatekeeper site. FEBS Letters 571 43-49. (doi:10.1016/j.febslet.2004.06.050)

Al-Dhaheri MH \& Rowan BG 2006 Application of phosphorylation sitespecific antibodies to measure nuclear receptor signaling: characterization of novel phosphoantibodies for estrogen receptor? Nuclear Receptor Signaling 4 e007. (doi:10.1621/nrs.04007)

Araujo JC, Trudel GC, Saad F, Armstrong AJ, Yu EY, Bellmunt J, Wilding G, McCaffrey J, Serrano SV, Matveev VB et al. 2013 Docetaxel and dasatinib or placebo in men with metastatic castration-resistant prostate cancer (READY): a randomised, double-blind phase 3 trial. Lancet Oncology 14 1307-1316. (doi:10.1016/S1470-2045(13)70479-0)

Askew EB, Bai S, Blackwelder AJ \& Wilson EM 2010 Transcriptional synergy between melanoma antigen gene protein-A11 (MAGE-11) and p300 in androgen receptor signaling. Journal of Biological Chemistry $\mathbf{2 8 5}$ 21824-21836. (doi:10.1074/jbc.M110.120600)

Bai S, He B \& Wilson EM 2005 Melanoma antigen gene protein MAGE-11 regulates androgen receptor function by modulating the interdomain interaction. Molecular and Cellular Biology 25 1238-1257. (doi:10.1128/ MCB.25.4.1238-1257.2005)

Beltran H, Rickman DS, Park K, Chae SS, Sboner A, MacDonald TY, Wang Y, Sheikh KL, Terry S, Tagawa ST et al. 2011 Molecular characterization of neuroendocrine prostate cancer and identification of new drug targets. Cancer Discovery 1 487-495. (doi:10.1158/2159-8290.CD-11-0130)

Brumbaugh K, Johnson W, Liao W-C, Lin M-S, Houchins JP, Cooper J, Stoesz S \& Campos-Gonzalez R 2011 Overview of the generation, validation, and application of phosphosite-specific antibodies. Methods in Molecular Biology 717 3-43. (doi: 10.1007/978-1-61779-024-9_1)

Bubulya A, Wise SC, Shen XQ \& Burmeister LA 1996 c-Jun can mediate androgen receptor-induced transactivation. Journal of Biological Chemistry 271 24583-24589. (doi:10.1074/jbc.271.40.24583)

Bubulya A, Zhou XF, Shen XQ, Fisher CJ \& Shemshedini L 2000 c-Jun targets amino terminus of androgen receptor in regulating androgenresponsive transcription. Endocrine 13 55-62. (doi:10.1385/ ENDO:13:1:55)

Bubulya A, Chen SY, Fisher CJ, Zheng Z, Shen XQ \& Shemshedini L 2001 c-Jun potentiates the functional interaction between the amino and carboxyl termini of the androgen receptor. Journal of Biological Chemistry 276 44704-44711. (doi:10.1074/jbc.M107346200)

Buschhorn HM, Klein RR, Chambers SM, Hardy MC, Green S, Bearss D \& Nagle RB 2005 Aurora-A over-expression in high-grade PIN lesions and prostate cancer. Prostate 64 341-346. (doi:10.1002/pros.20247)

Cen B, Mahajan S, Wang W \& Kraft AS 2013 Elevation of receptor tyrosine kinases by small molecule AKT inhibitors in prostate cancer is mediated by Pim-1. Cancer Research 73 3402-3411. (doi:10.1158/0008-5472. CAN-12-4619)

Chao SH \& Price DH 2001 Flavopiridol inactivates P-TEFb and blocks most RNA polymerase II transcription in vivo. Journal of Biological Chemistry 276 31793-31799. (doi:10.1074/jbc.M102306200)

Chen S, Xu Y, Yuan X, Bubley GJ \& Balk SP 2006 Androgen receptor phosphorylation and stabilization in prostate cancer by cyclindependent kinase 1. PNAS 103 15969-74. (doi:10.1073/pnas. 0604193103)

Chen S, Gulla S, Cai C \& Balk SP 2012 Androgen receptor serine 81 phosphorylation mediates chromatin binding and transcriptional activation. Journal of Biological Chemistry 287 8571-8583. (doi:10.1074/ jbc.M111.325290)

Chi Y, Zhang C, Zong H, Hong Y, Kong X, Liu H, Zou W, Wang Y, Yun X \& $\mathrm{Gu} J 2011$ Thr-370 is responsible for CDK11(p58) autophosphorylation, dimerization, and kinase activity. Journal of Biological Chemistry 286 1748-1757. (doi:10.1074/jbc.M110.107367)

Chymkowitch P, Le May N, Charneau P, Compe E \& Egly JM 2011 The phosphorylation of the androgen receptor by TFIIH directs the ubiquitin/proteasome process. EMBO Journal 30 468-479. (doi:10.1038/emboj.2010.337) 
Comuzzi B, Lambrinidis L, Rogatsch H, Godoy-Tundidor S, Knezevic N, Krhen I, Marekovic Z, Bartsch G, Klocker H, Hobisch A et al. 2003 The transcriptional co-activator cAMP response element-binding protein-binding protein is expressed in prostate cancer and enhances androgen- and anti-androgen-induced androgen receptor function. American Journal of Pathology 162 233-241. (doi:10.1016/S00029440(10)63814-X)

Dai B, Chen H, Guo S, Yang X, Linn DE, Sun F, Li W, Guo Z, Xu K, Kim O et al. 2010 Compensatory upregulation of tyrosine kinase Etk/BMX in response to androgen deprivation promotes castration-resistant growth of prostate cancer cells. Cancer Research 70 5587-5596. (doi:10.1158/ 0008-5472.CAN-09-4610)

DaSilva J, Gioeli D, Weber MJ \& Parsons SJ 2009 The neuroendocrinederived peptide parathyroid hormone-related protein promotes prostate cancer cell growth by stabilizing the androgen receptor. Cancer Research 69 7402-7411. (doi:10.1158/0008-5472.CAN-08-4687)

Dhavan R \& Tsai LH 2001 A decade of CDK5. Nature Reviews. Molecular Cell Biology 2 749-759. (doi:10.1038/35096019)

Doesburg P, Kuil CW, Berrevoets CA, Steketee K, Faber PW, Mulder E, Brinkmann AO \& Trapman J 1997 Functional in vivo interaction between the amino-terminal, transactivation domain and the ligand binding domain of the androgen receptor. Biochemistry 36 1052-1064. (doi:10.1021/bi961775g)

Fronsdal K, Engedal N, Slagsvold T \& Saatcioglu F 1998 CREB binding protein is a coactivator for the androgen receptor and mediates cross-talk with AP-1. Journal of Biological Chemistry 273 31853-31859. (doi:10.1074/jbc.273.48.31853)

Furukawa J, Miyake H, Takenaka A, Hara I \& Fujisawa M 2007 Persistent expression of Aurora-A after neoadjuvant hormonal therapy as a predictor of a poor clinical outcome in patients undergoing radical prostatectomy for prostate cancer. BJU International 100 310-314. (doi:10.1111/j.1464-410X.2007.06982.x)

Gelmann EP 2002 Molecular biology of the androgen receptor. Journal of Clinical Oncology 20 3001-3015. (doi:10.1200/JCO.2002.10.018)

Gioeli D \& Paschal BM 2012 Post-translational modification of the androgen receptor. Molecular and Cellular Endocrinology 352 70-78. (doi:10.1016/j.mce.2011.07.004)

Gioeli D, Mandell JW, Petroni GR, Frierson HF \& Weber MJ 1999 Activation of mitogen-activated protein kinase aassociated with prostate cancer progression. Cancer Research 59 279-284.

Gioeli D, Ficarro SB, Kwiek JJ, Aaronson D, Hancock M, Catling AD, White FM, Christian RE, Settlage RE, Shabanowitz J et al. 2002 Androgen receptor phosphorylation. Regulation and identification of the phosphorylation sites. Journal of Biological Chemistry 277 29304-29314. (doi:10.1074/jbc.M204131200)

Gioeli D, Black BE, Gordon V, Spencer A, Kesler CT, Eblen ST, Paschal BM \& Weber MJ 2006 Stress kinase signaling regulates androgen receptor phosphorylation, transcription, and localization. Molecular Endocrinology 20 503-515. (doi:10.1210/me.2005-0351)

Gioeli D, Wunderlich W, Sebolt-Leopold J, Bekiranov S, Wulfkuhle JD, Petricoin EF III, Conaway M \& Weber MJ 2011 Compensatory pathways induced by MEK inhibition are effective drug targets for combination therapy against castration-resistant prostate cancer. Molecular Cancer Therapeutics 10 1581-1590. (doi:10.1158/1535-7163. MCT-10-1033)

Gordon V, Bhadel S, Wunderlich W, Zhang J, Ficarro SB, Mollah SA, Shabanowitz J, Hunt DF, Xenarios I, Hahn WC et al. 2010 CDK9 regulates AR promoter selectivity and cell growth through serine 81 phosphorylation. Molecular Endocrinology 24 2267-2280. (doi:10.1210/me.2010-0238)

Gregory CW, Fei X, Ponguta LA, He B, Bill HM, French FS \& Wilson EM 2004 Epidermal growth factor increases coactivation of the androgen receptor in recurrent prostate cancer. Journal of Biological Chemistry 279 7119-7130. (doi:10.1074/jbc.M307649200)

Guo Z, Dai B, Jiang T, Xu K, Xie Y, Kim O, Nesheiwat I, Kong X, Melamed J, Handratta VD et al. 2006 Regulation of androgen receptor activity by tyrosine phosphorylation. Cancer Cell 10 309-319. (doi:10.1016/j.ccr. 2006.08.021)

Ha S, Iqbal NJ, Mita P, Ruoff R, Gerald WL, Lepor H, Taneja SS, Lee P, Melamed J \& Garabedian MJ 2012 Phosphorylation of the androgen receptor by PIM1 in hormone refractory prostate cancer. Oncogene 32 3992-4000. (doi:10.1038/onc.2012.412)

Harper JW \& Elledge SJ 1998 The role of Cdk7 in CAK function, a retro-retrospective. Genes and Development 12 285-289. (doi:10.1101/ gad.12.3.285)

He B, Bai S, Hnat AT, Kalman RI, Minges JT, Patterson C \& Wilson EM 2004 An androgen receptor NH2-terminal conserved motif interacts with the COOH terminus of the Hsp70-interacting protein (CHIP). Journal of Biological Chemistry 279 30643-30653. (doi:10.1074/jbc.M403117200)

Heemers HV \& Tindall DJ 2007 Androgen receptor (AR) coregulators: a diversity of functions converging on and regulating the AR transcriptional complex. Endocrine Reviews 28 778-808. (doi:10.1210/ er.2007-0019)

Heinlein CA \& Chang C 2002 Androgen receptor (AR) coregulators: an overview. Endocrine Reviews 23 175-200.

Hickey TE, Robinson JLL, Carroll JS \& Tilley WD 2012 Minireview: the androgen receptor in breast tissues: growth inhibitor, tumor suppressor, oncogene? Molecular Endocrinology 26 1252-1267. (doi:10.1210/me.2012-1107)

Hsu F-N, Chen M-C, Chiang M-C, Lin E, Lee Y-T, Huang P-H, Lee G-S \& Lin H 2011 Regulation of androgen receptor and prostate cancer growth by cyclin-dependent kinase 5. Journal of Biological Chemistry $\mathbf{2 8 6}$ 33141-33149. (doi:10.1074/jbc.M111.252080)

Hübner A, Mulholland DJ, Standen CL, Karasarides M, Cavanagh-Kyros J, Barrett T, Chi H, Greiner DL, Tournier C, Sawyers CL et al. 2012 JNK and PTEN cooperatively control the development of invasive adenocarcinoma of the prostate. PNAS 109 12046-12051. (doi:10.1073/ pnas.1209660109)

Kasina S \& Macoska JA 2012 The CXCL12/CXCR4 axis promotes ligandindependent activation of the androgen receptor. Molecular and Cellular Endocrinology 351 249-263. (doi:10.1016/j.mce.2011.12.015)

Kinkade CW, Castillo-Martin M, Puzio-Kuter A, Yan J, Foster TH, Gao H, Sun Y, Ouyang X, Gerald WL, Cordon-Cardo C et al. 2008 Targeting AKT/mTOR and ERK MAPK signaling inhibits hormone-refractory prostate cancer in a preclinical mouse model. Journal of Clinical Investigation 118 3051-3064. (doi:10.1172/JCI34764)

Kotaja N, Karvonen U, Janne OA \& Palvimo JJ 2002a The nuclear receptor interaction domain of GRIP1 is modulated by covalent attachment of SUMO-1. Journal of Biological Chemistry 277 30283-30288. (doi:10.1074/jbc.M204768200)

Kotaja N, Karvonen U, Janne OA \& Palvimo JJ 2002 $b$ PIAS proteins modulate transcription factors by functioning as SUMO-1 ligases. Molecular and Cellular Biology 22 5222-5234. (doi:10.1128/MCB.22.14. 5222-5234.2002)

Lagarde WH, Blackwelder AJ, Minges JT, Hnat AT, French FS \& Wilson EM 2012 Androgen receptor exon 1 mutation causes androgen insensitivity by creating phosphorylation site and inhibiting melanoma antigenA11 activation of NH2- and carboxyl-terminal interaction-dependent transactivation. Journal of Biological Chemistry 287 10905-10915. (doi:10.1074/jbc.M111.336081)

Langley E, Zhou ZX \& Wilson EM 1995 Evidence for an anti-parallel orientation of the ligand-activated human androgen receptor dimer. Journal of Biological Chemistry 270 29983-29990. (doi:10.1074/jbc. 270.10.5251)

Lin HK, Yeh S, Kang HY \& Chang C 2001 Akt suppresses androgen-induced apoptosis by phosphorylating and inhibiting androgen receptor. PNAS 98 7200-7205. (doi:10.1073/pnas.121173298)

Lin HK, Hu YC, Yang L, Altuwaijri S, Chen YT, Kang HY \& Chang C 2003 Suppression versus induction of androgen receptor functions by the phosphatidylinositol 3-kinase/Akt pathway in prostate cancer LNCaP cells with different passage numbers. Journal of Biological Chemistry $\mathbf{2 7 8}$ 50902-50907. (doi:10.1074/jbc.M300676200) 
Linja MJ, Savinainen KJ, Saramaki OR, Tammela TL, Vessella RL \& Visakorpi T 2001 Amplification and overexpression of androgen receptor gene in hormone-refractory prostate cancer. Cancer Research $613550-3555$.

Linn DE, Yang X, Xie Y, Alfano A, Deshmukh D, Wang X, Shimelis H, Chen H, Li W, Xu K et al. 2012 Differential regulation of androgen receptor by PIM-1 kinases via phosphorylation-dependent recruitment of distinct ubiquitin E3 ligases. Journal of Biological Chemistry 287 22959-22968. (doi:10.1074/jbc.M111.338350)

Liu Y, Karaca M, Zhang Z, Gioeli D, Earp HS \& Whang YE 2010 Dasatinib inhibits site-specific tyrosine phosphorylation of androgen receptor by Ack1 and Src kinases. Oncogene 29 3208-3216. (doi:10.1038/onc.2010.103)

Liu T, Li Y, Gu H, Zhu G, Li J, Cao L \& Li F 2013 p21-Activated kinase 6 (PAK6) inhibits prostate cancer growth via phosphorylation of androgen receptor and tumorigenic E3 ligase murine double minute-2 (Mdm2). Journal of Biological Chemistry 288 3359-3369. (doi:10.1074/ jbc.M112.384289)

Lubahn DB, Joseph DR, Sullivan PM, Willard HF, French FS \& Wilson EM 1988 Cloning of human androgen receptor complementary DNA and localization to the X chromosome. Science 240 327-330. (doi:10.1126/ science.3353727)

Mahajan NP, Liu Y, Majumder S, Warren MR, Parker CE, Mohler JL, Earp HS \& Whang YE 2007 Activated Cdc42-associated kinase Ack1 promotes prostate cancer progression via androgen receptor tyrosine phosphorylation. PNAS 104 8438-8443. (doi:10.1073/pnas.0700420104)

Mahajan K, Challa S, Coppola D, Lawrence H, Luo Y, Gevariya H, Zhu W, Chen YA, Lawrence NJ \& Mahajan NP 2010 Effect of Ack1 tyrosine kinase inhibitor on ligand-independent androgen receptor activity. Prostate 70 1274-1285. (doi:10.1002/pros.21163)

Mahajan K, Coppola D, Rawal B, Chen YA, Lawrence HR, Engelman RW, Lawrence NJ \& Mahajan NP 2012 Ack1-mediated androgen receptor phosphorylation modulates radiation resistance in castration-resistant prostate cancer. Journal of Biological Chemistry 287 22112-22122. (doi:10.1074/jbc.M112.357384)

Malumbres M \& Barbacid M 2009 Cell cycle, CDKs and cancer: a changing paradigm. Nature Reviews. Cancer 9 153-166. (doi:10.1038/nrc2602)

Mandell JW, Hussaini IM, Zecevic M, Weber MJ \& VandenBerg SR 1998 In situ visualization of intratumor growth factor signaling: immunohistochemical localization of activated ERK/MAP kinase in glial neoplasms. American Journal of Pathology 153 1411-1423. (doi:10.1016/ S0002-9440(10)65728-8)

McCall P, Gemmell LK, Mukherjee R, Bartlett JM \& Edwards J 2008 Phosphorylation of the androgen receptor is associated with reduced survival in hormone-refractory prostate cancer patients. British Journal of Cancer 98 1094-1101. (doi:10.1038/sj.bjc.6604152)

McCall P, Adams CE, Willder JM, Bennett L, Qayyum T, Orange C, Underwood MA \& Edwards J 2013 Androgen receptor phosphorylation at serine 308 and serine 791 predicts enhanced survival in castrate resistant prostate cancer patients. International Journal of Molecular Sciences 14 16656-16671. (doi:10.3390/ijms140816656)

McKenna NJ \& O'Malley BW 2002a Minireview: nuclear receptor coactivators - an update. Endocrinology 143 2461-2465.

McKenna NJ \& O'Malley BW 2002b Combinatorial control of gene expression by nuclear receptors and coregulators. Cell 108 465-474. (doi:10.1016/S0092-8674(02)00641-4)

McNally JG, Müller WG, Walker D, Wolford R \& Hager GL 2000 The glucocorticoid receptor: rapid exchange with regulatory sites in living cells. Science 287 1262-1265. (doi:10.1126/science.287.5456.1262)

Mellinghoff IK, Tran C \& Sawyers CL 2002 Growth inhibitory effects of the dual ErbB1/ErbB2 tyrosine kinase inhibitor PKI-166 on human prostate cancer xenografts. Cancer Research 62 5254-5259.

Mosquera JM, Beltran H, Park K, MacDonald TY, Robinson BD, Tagawa ST, Perner S, Bismar TA, Erbersdobler A, Dhir R et al. 2013 Concurrent AURKA and MYCN gene amplifications are harbingers of lethal treatment-related neuroendocrine prostate cancer. Neoplasia 15 1-10.

http://erc.endocrinology-journals.org DOI: 10.1530/ERC-13-0472
(C) 2014 Society for Endocrinology Printed in Great Britain
Nessler-Menardi C, Jotova I, Culig Z, Eder IE, Putz T, Bartsch G \& Klocker H 2000 Expression of androgen receptor coregulatory proteins in prostate cancer and stromal-cell culture models. Prostate 45 124-131. (doi:10.1002/1097-0045(20001001)45:2<124::AID-PROS6>3.0.CO;2-7)

Olshavsky NA, Groh EM, Comstock CE, Morey LM, Wang Y, Revelo MP, Burd C, Meller J \& Knudsen KE 2008 Cyclin D3 action in androgen receptor regulation and prostate cancer. Oncogene 27 3111-3121. (doi:10.1038/sj.onc.1210981)

Palazzolo I, Burnett BG, Young JE, Brenne PL, La Spada AR, Fischbeck KH, Howell BW \& Pennuto M 2007 Akt blocks ligand binding and protects against expanded polyglutamine androgen receptor toxicity. Human Molecular Genetics 16 1593-1603. (doi:10.1093/hmg/ddm109)

Ponguta LA, Gregory CW, French FS \& Wilson EM 2008 Site-specific androgen receptor serine phosphorylation linked to epidermal growth factor-dependent growth of castration-recurrent prostate cancer. Journal of Biological Chemistry 283 20989-21001. (doi:10.1074/ jbc.M802392200)

Ren Q, Zhang L, Ruoff R, Ha S, Wang J, Jain S, Reuter V, Gerald W, Giri DD, Melamed J et al. 2013 Expression of androgen receptor and its phosphorylated forms in breast cancer progression. Cancer 119 2532-2540. (doi:10.1002/cncr.28092)

Reutens AT, Fu M, Wang C, Albanese C, McPhaul MJ, Sun Z, Balk SP, Janne OA, Palvimo JJ \& Pestell RG 2001 Cyclin D1 binds the androgen receptor and regulates hormone-dependent signaling in a p300/ CBP-associated factor (P/CAF)-dependent manner. Molecular Endocrinology 15 797-811.

Rocha J, Zouanat F, Zoubeidi A, Hamel L, Benidir T, Scarlata E, Brimo F, Aprikian A \& Chevalier S 2013 The Fer tyrosine kinase acts as a downstream interleukin-6 effector of androgen receptor activation in prostate cancer. Molecular and Cellular Endocrinology 381 140-9. (doi:10.1016/j.mce.2013.07.017)

Saris CJ, Domen J \& Berns A 1991 The pim-1 oncogene encodes two related protein-serine/threonine kinases by alternative initiation at AUG and CUG. EMBO Journal 10 655-664.

Sarker D, Reid A, Yap T \& de Bono JS 2009 Targeting the PI3K/AKT pathway for the treatment of prostate cancer. Clinical Cancer Research $\mathbf{1 5}$ 4799-4805. (doi:10.1158/1078-0432.CCR-08-0125)

Shah N, Pang B, Yeoh K-G, Thorn S, Chen CS, Lilly MB \& Salto-Tellez M 2008 Potential roles for the PIM1 kinase in human cancer - a molecular and therapeutic appraisal. European Journal of Cancer 44 2144-2151. (doi:10.1016/j.ejca.2008.06.044)

Shen MM \& Abate-Shen C 2007 Pten inactivation and the emergence of androgen-independent prostate cancer. Cancer Research 67 6535-6538. (doi:10.1158/0008-5472.CAN-07-1271)

Shu SK, Liu Q, Coppola D \& Cheng JQ 2010 Phosphorylation and activation of androgen receptor by Aurora-A. Journal of Biological Chemistry 285 33045-33053. (doi:10.1074/jbc.M110.121129)

Sun C, Dobi A, Mohamed A, Li H, Thangapazham RL, Furusato B, Shaheduzzaman S, Tan S-H, Vaidyanathan G, Whitman E et al. 2008 TMPRSS2-ERG fusion, a common genomic alteration in prostate cancer activates C-MYC and abrogates prostate epithelial differentiation. Oncogene 27 5348-5353. (doi:10.1038/onc.2008.183)

Taneja SS, Ha S, Swenson NK, Huang HY, Lee P, Melamed J, Shapiro E, Garabedian MJ \& Logan SK 2005 Cell-specific regulation of androgen receptor phosphorylation in vivo. Journal of Biological Chemistry $\mathbf{2 8 0}$ 40916-40924. (doi:10.1074/jbc.M508442200)

Tillman K, Oberfield JL, Shen XQ, Bubulya A \& Shemshedini L 1998 c-Fos dimerization with c-Jun represses c-Jun enhancement of androgen receptor transactivation. Endocrine 9 193-200. (doi:10.1385/ ENDO:9:2:193)

Varisli L, Gonen-Korkmaz C, Syed HM, Bogurcu N, Debelec-Butuner B, Erbaykent-Tepedelen B \& Korkmaz KS 2012 Androgen regulated HN1 leads proteosomal degradation of androgen receptor (AR) and negatively influences AR mediated transactivation in prostate cells. Molecular and Cellular Endocrinology 350 107-117. (doi:10.1016/j.mce. 2011.11.027) 
Wang X, Yeh S, Wu G, Hsu CL, Wang L, Chiang T, Yang Y, Guo Y \& Chang C 2001 Identification and characterization of a novel androgen receptor coregulator ARA267- $\alpha$ in prostate cancer cells. Journal of Biological Chemistry 276 40417-40423. (doi:10.1074/jbc.M104765200)

Wang J, Kim J, Roh M, Franco OE, Hayward SW, Wills ML \& Abdulkadir SA 2010 Pim1 kinase synergizes with c-MYC to induce advanced prostate carcinoma. Oncogene 29 2477-2487. (doi:10.1038/onc.2010.10)

Wen Y, Hu MC, Makino K, Spohn B, Bartholomeusz G, Yan DH \& Hung MC 2000 HER-2/neu promotes androgen-independent survival and growth of prostate cancer cells through the Akt pathway. Cancer Research $\mathbf{6 0}$ 6841-6845.

Willder JM, Heng SJ, McCall P, Adams CE, Tannahill C, Fyffe G, Seywright M, Horgan PG, Leung HY, Underwood MA et al. 2013 Androgen receptor phosphorylation at serine 515 by Cdk1 predicts biochemical relapse in prostate cancer patients. British Journal of Cancer 108 139-148. (doi:10.1038/bjc.2012.480)

Wise SC, Burmeister LA, Zhou XF, Bubulya A, Oberfield JL, Birrer MJ \& Shemshedini L 1998 Identification of domains of c-Jun mediating androgen receptor transactivation. Oncogene 16 2001-2009. (doi:10. 1038/sj.onc.1201697)

Wood NT, Meek DW \& Mackintosh C 2009 14-3-3 Binding to Pimphosphorylated Ser166 and Ser186 of human Mdm2 - potential interplay with the PKB/Akt pathway and p14(ARF). FEBS Letters 583 615-620. (doi:10.1016/j.febslet.2009.01.003)

Wu K, Liu J, Tseng S-F, Gore C, Ning Z, Sharifi N, Fazli L, Gleave M, Kapur P, Xiao G et al. 2014 The role of DAB2IP in androgen receptor activation during prostate cancer progression. Oncogene 33 1954-1963. (doi:10.1038/onc.2013.143)

Xu K, Shimelis H, Linn DE, Jiang R, Yang X, Sun F, Guo Z, Chen H, Li W, Kong X et al. 2009 Regulation of androgen receptor transcriptional activity and specificity by RNF6-induced ubiquitination. Cancer Cell $\mathbf{1 5}$ 270-282. (doi:10.1016/j.ccr.2009.02.021)

Yang CS, Xin HW, Kelley JB, Spencer A, Brautigan DL \& Paschal BM 2007 Ligand binding to the androgen receptor induces conformational changes that regulate phosphatase interactions. Molecular and Cellular Biology 27 3390-3404. (doi:10.1128/ MCB.02411-06)

Yeh S, Lin HK, Kang HY, Thin TH, Lin MF \& Chang C 1999 From HER2/Neu signal cascade to androgen receptor and its coactivators: a novel pathway by induction of androgen target genes through MAP kinase in prostate cancer cells. PNAS 96 5458-5463. (doi:10.1073/ pnas.96.10.5458)

Zellweger T, Stürm S, Rey S, Zlobec I, Gsponer JR, Rentsch CA, Terracciano LM, Bachmann A, Bubendorf L \& Ruiz C 2013 Estrogen receptor $\beta$ expression and androgen receptor phosphorylation correlate with a poor clinical outcome in hormone-naive prostate cancer and are elevated in castration-resistant disease. Endocrine-Related Cancer 20 403-413. (doi:10.1530/ ERC-12-0402)

Zhang Y, Wang Z, Li X \& Magnuson NS 2008 Pim kinase-dependent inhibition of c-Myc degradation. Oncogene 27 4809-4819. (doi:10.1038/onc.2008.123)

Zippo A, De Robertis A, Serafini R \& Oliviero S 2007 PIM1-dependent phosphorylation of histone $\mathrm{H} 3$ at serine 10 is required for MYCdependent transcriptional activation and oncogenic transformation. Nature Cell Biology 9 932-944. (doi:10.1038/ncb1618)

Zong H, Chi Y, Wang Y, Yang Y, Zhang L, Chen H, Jiang J, Li Z, Hong Y, Wang $\mathrm{H}$ et al. 2007 Cyclin D3/CDK11p58 complex is involved in the repression of androgen receptor. Molecular and Cellular Biology 27 7125-7142. (doi:10.1128/МСB.01753-06)

Received in final form 20 December 2013

Accepted 13 January 2014

Made available online as an Accepted Preprint

14 January 2014
(C) 2014 Society for Endocrinology Printed in Great Britain 